East African Medical Journal Vol. 86 May 2009

STRATIFICATION OF PERSONS WITH DIABETES INTO RISK CATEGORIES FOR FOOT ULCERATION

E. Mugambi-Nturibi, MBChB, MMed, Senior House Officer, Kenyatta National Hospital, P.O. Box 29774-00202, Nairobi, Kenya, C. F. Otieno, MBChB, MMed, Senior Lecturer, T.O.O. Kwasa, MBChB, MMed, Senior Lecturer, G. O. Oyoo, MBChB, MMed, Senior Lecturer and K. Acharya, MBChB, MRCP (Ireland), Senior Lecturer, Department of Clinical Medicine and Therapeutics, College of Health Sciences, University of Nairobi, P.O. Box 19676-00202, Nairobi, Kenya

Request for reprints to: Dr. E. Mugambi-Nturibi, P.O. Box 29774-00202, Nairobi, Kenya

\title{
STRATIFICATION OF PERSONS WITH DIABETES INTO RISK CATEGORIES FOR FOOT ULCERATION
}

\author{
E. MUGAMBI-NTURIBI, C.F. OTIENO, T.O.O. KWASA, G. O. OYOO and K. ACHARYA
}

\begin{abstract}
Background: Patients with diabetes mellitus are at a higher risk of lower extremity complications as compared to their non-diabetic counterparts.

Objective: To study risk factors for diabetic foot ulcer disease and stratify patients with diabetes into risk categories for foot ulceration.

Design: Cross-sectional descriptive study over five months period.

Setting: Diabetic outpatient clinic, at the Kenyatta National Hospital.

Subjects: Two hundred and eighteen ambulatory subjects with diabetes mellitus without active foot lesions.

Results: The prevalence of previous foot ulceration was $16 \%$ while that of previous amputation was $8 \%$. Neuropathy was present in $42 \%$ of the study subjects and was significantly associated with age, male gender, duration of diabetes, random blood sugar, systolic blood pressure and the presence of foot deformity. Peripheral arterial disease was present in $12 \%$ and showed significant association with male gender. Foot deformities were observed in $46 \%$ of study subjects and were significantly associated with age, male gender, and presence of neuropathy. Subsequently $57 \%$ were categorised into IWGDF group 0 - no neuropathy, $10 \%$ were placed in group 1- neuropathy alone, $16 \%$ were put in group 2 - neuropathy plus either peripheral arterial disease or foot deformity and $17 \%$ were placed in risk group 3 - previous foot ulceration/amputation.

Conclusion: More than one third (33\%) of diabetic patients were found to be at high risk for future foot ulceration (IWGDF groups 2 and 3). Published evidence exists that shows improved outcomes with interventions targeting individual patients with diabetes at high-risk of foot ulceration. Long term prospective studies to determine outcomes for the different risk categories should be carried out locally.
\end{abstract}

\section{INTRODUCTION}

By the year 2010 it is estimated that 221 million people will be affected with diabetes globally (1). It is thought that the life time risk of developing a foot ulcer in a diabetic patient (type 1 or 2) is approximately $15 \%$ (2).

Diabetic foot ulcers are responsible for frequent and prolonged admission periods (3). Epidemiological studies suggest that foot ulcers precede about $85 \%$ of non-traumatic lower extremity amputations in individuals with diabetes (4). The five year mortality following amputation has been found to be between 39\%-68\% in various studies (5-7). In a 1999 study, the prevalence of diabetic foot ulcers at Kenyatta
National Hospital was 46 per 1000 diabetic patients, with foot ulcers accounting for $12 \%$ of all diabetic admissions. The morbidity attributable to diabetic foot ulcer disease was underscored by the finding that the mean ulcer duration was 17 weeks and that $50 \%$ of patients presented with Wagner stage 2 ulcers whilst $25 \%$ had advanced Wagner stage 4 ulcers (8).

Diabetic foot ulcers are a cause of potentially preventable morbidity, tragic sequelae, notably lower extremity amputation with its grave socio-economic consequences, and mortality.

Several reports indicate that adequate foot examinations are often not performed in diabetic patients (9-10). A lack of clear understanding of the most important criteria to include in a screening 
examination may be contributory (11). Furthermore, with the increasing number of patients with diabetes, it is difficult to provide in-depth preventive foot services for every patient with the disease owing to constraints in resources $(12,13)$.

Allocation of appropriate intervention modalities in high risk diabetic patients has been shown to decrease the rate of re-ulceration by up to $60 \%$ and lower extremity amputation by up to $85 \%$ (13).

Risk stratification allows prioritisation of resources to high risk populations where they will have the greatest impact.

\section{MATERIALS AND METHODS}

For each patient, the demographic history was taken and the patient's clinic record consulted. A simple questionnaire was then administered to collect data concerning previous ulceration, amputation, peripheral vascular disease, neurological deficit, and foot care knowledge. Height was measured against a vertical scale to the nearest half centimetre, with the patient standing erectand without shoes. Weight was measured to the nearest half kilogram with the patient in light clothing, without shoes and using a standard weighing chair in the clinic. BMI was calculated as the weight in kilograms divided by the square of the height in metres and the degree of obesity classified as follows (14).

\begin{tabular}{ll}
\hline BMI $\left(\mathrm{kg} / \mathrm{m}^{2}\right)$ & Degree of obesity \\
\hline$<25$ & Non obese \\
$25-29.9$ & Overweight \\
$30-39.9$ & Obese \\
$>40$ & Very obese \\
\hline
\end{tabular}

Blood pressure was measured with the patient in the supine position after a rest period of 5 minutes, using standard procedure. Hypertension was defined as follows:

\begin{tabular}{lcc}
\hline Category & $\begin{array}{c}\text { Systolic BP } \\
(\mathrm{mmHg})\end{array}$ & $\begin{array}{c}\text { Diastolic BP } \\
(\mathrm{mmHg})\end{array}$ \\
\hline Optimal & $<120$ & $<80$ \\
Normal & $<130$ & $<85$ \\
High normal & $130-139$ & $85-89$ \\
Hypertension & & \\
$\quad$ Stage 1 & $140-159$ & $90-99$ \\
$\quad$ Stage 2 & $160-179$ & $100-109$ \\
$\quad$ Stage 3 & $>180$ & $>110$ \\
$\quad$ Isolated systolic & & \\
$\quad$ hypertension & $>140$ & $<90$ \\
\hline
\end{tabular}

The feet were then examined:

Inspection: The patient was observed while walking from one end of the examination room to the other and any abnormality of gait due to pain or deformity recorded. With the patient standing, the feet and the ankles were inspected for hind foot deformities (valgus/varus), pes planus, pes cavus, toe deformities (hallux valgus, claw toe, mallet toe, hammer toe) and prominent metatarsal heads. With the patient supine, the condition of the nails and skin was noted as was the presence of swellings. The presence of callosities was recorded. The presence of high risk lesions such as fungal infections was also recorded.

Palpation:The hind-foot, mid-foot and fore-foot were palpated to accurately localise any tenderness, swelling or deformity. The passive range of movement of the ankle joint, sub-talar and mid-tarsal joints was then assessed and each recorded as normal, or restricted. The individual toes were assessed to identify any restriction of movement, and this was recorded as normal or restricted. The posterior tibial pulse and the dorsalis pedis were then assessed and graded as normal, reduced or absent. The presence of blanching on elevation, rubor on dependance and delayed capillary refill was then assessed.

Neurological exam: For each foot the Achilles tendon reflex was tested using a standard patella hammer and a standard technique. The score below was assigned:
Absent (2 points for each foot)
Present with reinforcement (1 point for each foot)
Present without reinforcement ( 0 points)

Vibration sense was tested using a $128 \mathrm{HZ}$ tuning fork over the lateral and medial maleoli and the perception graded as:

$$
\begin{aligned}
& \text { Normal (0 points) } \\
& \text { Absent or reduced (1 point for each foot) }
\end{aligned}
$$

Pressure sensation was then tested using a 5.07 (10-g) monofilament. This was done at six points on the foot and recorded as normal or abnormal.

Pinpricksensation was assessed on the feet using a disposable pin and graded as:

$$
\begin{aligned}
& \text { Normal - (0 points) } \\
& \text { Absent or reduced - (1 point for each foot })
\end{aligned}
$$

Temperature sensation was assessed using a cold tuning fork after immersion in cold water, on the dorsum of the feet and the sensation graded as:

Normal - 0 points

Reduced (1 point for each foot) 
The neurological disability score was then determined and scored as:

0 to 2 - no neuropathy

3 to 5 - mild neuropathy

6 to 8 - moderate

9 to 10 - severe.

The score was doubled in patients with previous unilateral foot amputation.

Ankle Brachial Index $(A B I)$ determination: A hand held Doppler probe $(8 \mathrm{MHz})$ was held over the three pedal arteries (posterior tibial, dorsalis pedis, perforating peroneal) in turns while ablood pressure cuff wrapped around the ankle was inflated. The pressure at which the Doppler signal disappears was recorded as the systolic pressure in the artery as it passed under the cuff. The ratio of the highest pedal pressure to the highest brachial artery pressure determined by the Doppler method was recorded as the Ankle Brachial Pressure Index and interpreted as follows:
$>1.30$
Non compressible vessel
$0.91-1.30$
Normal
$0.41-0.90$
Mild-moc
$0.00-0.40$ disease
Severe peripheral arterial disease

A random blood sugar (RBS) level was then determined by aseptic pin prick using a standard glucometer.
Risk stratification: Patients were then placed into one of the following IWGDF risk categories:

$\begin{array}{ll}\text { Group } & \text { Category } \\ 0 & \text { No neuropathy } \\ 1 & \text { Neuropathy present } \\ & \text { Deformity absent } \\ & \text { PAD absent } \\ & \text { Neuropathy present, plus either } \\ 2 & \text { deformity or PAD or both } \\ 3 & \text { Previous ulcer } \\ & \text { Previous amputation }\end{array}$

Statistical analysis: Data was collected into a specially designed pro-forma and coded before input into a statistical computer package (SPSS version 12). Descriptive statistics were applied to continuous and categoricaldata from whichmeasuresofcentral tendency and proportions were derived.Inferentialstatistics were applied to determine associations betweenage, gender, blood sugar, measures of obesity and neuropathy / peripheral arterial disease/ foot deformity. Where comparisons were made a $\mathrm{p}$ - value of less than 0.05 was taken to be statistically significant.

\section{RESULTS}

A total of 218 ambulatory patients with diabetes mellitus were enrolled into the study. The baseline characteristics of the study participants are summarised in Table 1.

Table 1

Baseline characteristics by foot complication

\begin{tabular}{lcc}
\hline Characteristic & $\begin{array}{c}\text { Foot complication } \\
\text { (ulcer and/or } \\
\text { amputation) }\end{array}$ & $\begin{array}{c}\text { No foot } \\
\text { complication }\end{array}$ \\
\hline Number, $\mathrm{n}$, & 174 & 44 \\
Age, years (mean \pm SD) & $58.5 \pm 8.9$ & $55.9 \pm 9.8$ \\
Male \% & 39 & 55 \\
Duration of diabetes (years) & $16.1 \pm 4.1$ & $13.8 \pm 5.4$ \\
(mean \pm SD) & $11.7 \pm 3.9$ & $10 \pm 3.4$ \\
RBS $(\mathrm{mmol} / \mathrm{l})$ (mean $\pm \mathrm{SD})$ & $26.2 \pm 2.8$ & $24 \pm 3.7$ \\
BMI $\left(\mathrm{kg} / \mathrm{m}^{2}\right)($ mean $\pm \mathrm{SD})$ & $1.0 \pm 0.1$ & $1.1 \pm 0.3$ \\
ABl & $2.6 \pm 2.6$ & $1.32 \pm 0.8$ \\
NDS & 36 & 82 \\
Deformity $\%$ ) & $135 \pm 20$ & $144 \pm 12$ \\
SBP $(\mathrm{mmHg}$ (mean $\pm \mathrm{SD})$ & 1.1 & 2.3 \\
Current smoking $(\%)$ & & \\
\hline
\end{tabular}

Data presented as mean (SD); NDS = Neurological Disability Score; $A B I=$ Ankle Brachial Index 
The distribution of key variables in the different groups is represented in Table 2

Table 2

Patient characteristics in the different key ulceration risk categories

\begin{tabular}{|c|c|c|c|c|c|c|}
\hline \multirow[t]{2}{*}{ Characteristic } & \multicolumn{2}{|c|}{ Neuropathy } & \multicolumn{2}{|c|}{$\begin{array}{c}\text { Peripheral arterial } \\
\text { disease }\end{array}$} & \multicolumn{2}{|c|}{ Deformity } \\
\hline & Present & Absent & Present & Absent & Present & Absent \\
\hline Number, $n$, & 92 & 126 & 26 & 192 & 98 & 120 \\
\hline $\begin{array}{l}\text { Age (years) } \\
(\text { mean } \pm S D)\end{array}$ & $62.4 \pm 8.5^{*}$ & $56 \pm 8.7$ & $58.7 \pm 10$ & $57.6 \pm 8.9$ & $59.6 \pm 10^{*}$ & $56.7 \pm 7.8$ \\
\hline Male $\%$ & 58 & 33 & $33^{*}$ & 38 & 42 & 43 \\
\hline $\begin{array}{l}\text { Duration of diabetes } \\
\text { (yrs) (mean } \pm S D)\end{array}$ & $18.0 \pm 4.4^{*}$ & $14.6 \pm 4.2$ & $16.4 \pm 3.8$ & $15.5 \pm 4.6$ & $15.7 \pm 5$ & $15.6 \pm 4$ \\
\hline $\begin{array}{l}\mathrm{RBS}(\mathrm{mmol} / 1) \\
(\mathrm{mean} \pm \mathrm{sd})\end{array}$ & $12.9 \pm 4.3^{*}$ & $10.6 \pm 3.5$ & $12.8 \pm 3.3$ & $11.1 \pm 3.8$ & $11.1 \pm 4.3$ & $11.5 \pm 3.5$ \\
\hline $\mathrm{BMI}\left(\mathrm{kg} / \mathrm{m}^{2}\right)($ mean $\pm \mathrm{SD})$ & $26.3 \pm 3.4$ & $25.6 \pm 3$ & $27.2 \pm 2.6$ & $25.6 \pm 3.2$ & $25.5 \pm 3.2$ & $26.1 \pm 2.7$ \\
\hline $\mathrm{ABI}$ & $0.99 \pm 0.16$ & $1.03 \pm 0.13$ & $0.8 \pm 0.06$ & $1.03 \pm 0.12$ & $1.02 \pm 0.16$ & $1.01 \pm 0.13$ \\
\hline NDS & & & $4.5 \pm 3$ & $2.0 \pm 2.2$ & $2.3 \pm 1.9^{*}$ & $2.3 \pm 2.2$ \\
\hline Deformity $(\%)$ & $54^{*}$ & 41 & 35 & 46 & & \\
\hline $\mathrm{SBP}(\mathrm{mmHg})$ & $143 \pm 16^{*}$ & $134 \pm 19$ & $139 \pm 21$ & $137 \pm 19$ & $141 \pm 17$ & $134 \pm 19$ \\
\hline
\end{tabular}

Data presented as mean (SD); NDS = Neurological Disability Score; ABI = Ankle Brachial Index. * significant correlations $\mathrm{p}<0.05$

Subsequently the patients were stratified into the following IWDGP groups as shown in Table 3

Table 3

IWGDF categories

\begin{tabular}{lc}
\hline IWGDF group & Percentage of study subjects in each group \\
\hline 0 No neuropathy & 57 \\
1 Neuropathy alone & 10 \\
2 Neuropathy + PAD or deformity & 16 \\
3 Previous ulcer/ amputation & 17 \\
\hline
\end{tabular}

\section{DISCUSSION}

The prevalence of neuropathy in this study was $42 \%$ (92/218). Neuropathy was assessed through the use of the Neurological Disability Score. Using the same tool, Mwendwa et al (14) found a prevalence of peripheral neuropathy of $28 \%$ among patients with short-term type 2 diabetes ( $<2$ years) at Kenyatta National Hospital. However the mean duration of diabetes in their study group was 10.3 months in comparison to 15.9 years in this study. The mean age of the study population in the study of Mwendwa et al (14) was 53.7 years old as compared with the older age group in the present study with mean of
58 years old. Also the current study had more males i.e. (42\%) versus (37\%) in Mwendwa et al (14). Male gender has been shown to be strongly associated with neuropathy. Thus, the older age group, larger number of males, coupled with the increased duration of diabetes could have contributed to the higher prevalence of neuropathy in this particular study. The prevalence of neuropathy has been shown to vary widely among countries. Inter-observer variations have also occurred within similar populations. A comparative study of diabetic patients with foot lesions in Germany, India and Tanzania found that around $80 \%$ in each centre had peripheral neuropathy, but only 12 to $13 \%$ had evident peripheral arterial 
disease in Tanzania and India respectively, compared to $48 \%$ in Germany (15). The basal characteristics of the populations of study may vary amongst study subjects but evidence suggests that foot lesions in developing countries are largely neuropathicinorigin. Wikbald et at (16) in Tanzania found a prevalence of neuropathy in their patients of $28.1 \%$, PVD $12.50 \%$, while Elbagir et al (17) in Sudan found peripheral neuropathy of $37 \%$, PVD-10\%. Other studies have documented prevalence of peripheral neuropathy including, 27.8\% in the San Louis Diabetic Study (18) $28 \%$ in EURODIAB (19), 60\% in a Turkish study (20), and 66\% in the Rochester Study (21). A recent study reported from the middle-east found a high prevalence of $82 \%$ in Iran (22). The varying prevalence has been attributed to the lack of standardisation on the determination of neuropathy.

Equally important is the varying characteristics within/ amongst the study populations. In this study male gender was found to be significantly associated with neuropathy, $(p=0.01)$. This finding is similar to Mwendwa et al (14), the DCCT (21) and the San Louis valley diabetes study (16) Pickett (24) showed that females have higher nerve conduction speeds than males. Age was significantly associated with neuropathy in this study. The duration of diabetes was also significantly associated with the prevalence of neuropathy. Althoughstudies that have demonstrated the strong link between poor glycaemic control and neuropathy have used the $\mathrm{HBA}_{1 \mathrm{c}}$ as the marker for glycaemic control, this study was able to demonstrate that in our population the random blood sugar, a surrogate marker of metabolic control, is significantly associated with neuropathy $(p=0.011)$. The DCCT (21) showed a $60 \%$ reduction in the incidence of neuropathy among type 1 diabetic subjects in the group randomized to intensive glycaemic control. In type 2 diabetics the UKPDS (23) estimated that each $1 \%$ reduction in the $\mathrm{HBA}_{1 \mathrm{c}}$ was associated in a $35 \%$ relative reduction of all micro-vascular complications.

In this study, the prevalence of neuropathy was significantly increased with rise in systolic pressure $(p=0.034)$. EURODIAB (19) found that hypertension was associated with an odds ratio of $1.92(p<0=0.0001)$ of incident neuropathy. The UKPDS reported that all microvascular outcomes were reduced by between $24-56 \%$ by modest BP reduction to a mean of $144 / 82 \mathrm{mmhg}$ (23).

The prevalence of peripheral arterial disease (PAD) was $12 \%(26 / 218)$. The tool used was the Ankle Brachial Pressure Index as determined by the Doppler method. Nyamu et al (8), using clinical assessment found a prevalence of $52 \%$ in patients with diabetic foot ulcers. In Sudan, Elbaghir et al (17) reported a prevalence of $10 \%$. Wikbald et al (16) in Tanzania found a prevalence of $12 \%$. In the UK, the Edinburg artery study (25) estimated the prevalence to be as high as $20.1 \%$. In this study the association between peripheral arterial disease and age did not reach statistical significance although there was a trend towards increased occurrence with increasing age. Male gender was significantly associated with peripheral arterial disease $(p=0.001)$. Since the pathogenesis involves atherosclerosis, this finding is in keeping with published evidence that shows a strong link between male gender and atherosclerotic manifestations. A positive association between peripheral arterial disease and random blood sugar could not be demonstrated in this study. Although it has been shown that advanced glycaemic end products may have a role in the pathogenesis of peripheral arterial disease in diabetics, (26) very few controlled studies have investigated the association between glycaemic control and peripheral arterial disease. The atherosclerosis risk in communities study (27) found a positive, graded, and independent association between $A_{1 c}$ and PAD risk in diabetic adults. This association was stronger for clinical (symptomatic) PAD, whose manifestations may be related to microvascular insufficiency, than for low ABI. Although the mean Ankle Brachial Index was lower for patients with a BMI of more than $25 \mathrm{~kg} / \mathrm{m}^{2}$, the association between Ankle Brachial Index and Body Mass Index was not statistically significant $(p=0.138)$. To the authors' knowledge, no published well controlled studies thus far have demonstrated an unequivocal link between ABI and BMI. Systolic blood pressure was not associated with Ankle Brachial Index in this study $(\mathrm{p}=0.407)$. The Edinburg artery study (25) showed that raised systolic blood pressure was associated with an odds ratio of 1.22 of developing peripheral arterial disease.

The study concluded that increased mean levels of systolic blood pressure and triglycerides may help to explain the higher prevalence of PAD in diabetic subjects. The prevalence of foot deformities in this study was $46 \%$. Female gender had a significant statistical association with foot deformities $(\mathrm{p}=0.012)$. Females have generally been shown to have more foot deformities $(28,29)$ likely owing to the use of foot wear with restricted toe boxes and high heels. In our local setup, particularly in the rural areas, women are engaged in cultivation, fetching of firewood and water, and other activities that may result in accumulation of deformities particularly where they walk barefoot or wear inappropriate footwear. However, Abbas and Husam (32) in Basra has recently documented male gender as a risk factor for foot abnormalities in his study population. It is likely that foot deformities as a whole are more determined by gender roles as opposed to gender/ sex per se. However, the higher risk deformities, i.e. claw toe, hammer toe and prominent metatarsals were more frequent in males who had significant neuropathy, and thus this may 
explain theincreased prevalence of foot ulcers in men. As expected, deformity was significantly associated with advancing age which no doubt provides a greater opportunity for acquisition and accumulation of deformities. An important finding in this study also shown by Nyamu et al (8) is the significant association between foot deformity and neuropathy. Although it is generally held that neuropathy, by causing imbalance between the toe flexors and extensors may ultimately lead to claw toe deformity, very few studies have investigated the role of neuropathy in the causation of foot deformity. Carine et al (31), in their study, concluded that although important relationships between motor nerve conduction deficit and muscle weakness were demonstrated, it was still not clear whether abnormal nerve function, leading to a decrease in muscle strength, could be responsible for the development of foot deformities.

In conclusion, diabetes mellitus confers dramatic increase in risk of foot ulceration; however, available evidence suggests that this risk may be reduced by screening risk satisfaction and appropriate intervention measures (32-35). This study categorised $33 \%$ of the participant patients at intermediate to high risk groups of foot ulcerations. The non modifiable risk factors of foot ulceration documented in this study were; age, duration of diabetes, deformities and gender. However, the modifiable risk factors found in the study included; poor glycaemic control, inadequate education (of clinicians and patients) on foot care, neuropathy, high systolic blood pressure and peripheral artery disease (albeit at low prevalence). It is equally important to note that then risk stratification, is practical in a routine care selling ambulatory patients with diabetes.

More than one third of diabetics (33\%) are at high risk for future foot ulceration. Long term prospective studies should be carried out in a similar population locally to determine the risk of ulceration in the different categories since these may differ from studies done in the west.

\section{REFERENCES}

1. Bjork, S. The cost of diabetes and diabetes care. Diab. Res. Clin. Pract. 2001: 1 (suppl): S13-S18.

2. Jeffcoate, W.J. and Harding, K. G. Diabetic foot ulcers. Lancet. 2003; 361: 1545-1548.

3. Graves, E. J. National hospital discharge survey, annual summary. Vital Health. Statistics. 1990; 13: 1992-1996.

4. Ramsey, S. D., Newton, K., et al. Incidence, outcomes, and cost of foot ulcers in patients with diabetes. Diabetes Care. 1999; 22: 382-385.

5. Reiber, G. E., Pecoraro, R. E. and Koepsell, T. D. Risk factors for amputation in patients with diabetes mellitus: a case-control study. Ann. Intern. Med. 1992; 117: 97-105.
6. Miller, A. D., Van Buskirk, A., Verhok, W. and Miller, E. R. Diabetes related lower extremity amputations in New Jersey, 1979 to 1981. J. Med. Soc. New. Jersey 1985; 82: 723-726.

7. Nelson, R. G., Ghodes, D. M. and Everhart, J. E. Low extremity amputations in NIDDM: 12 year follow up study of pima indians. Diabetes care. 1988; 11: 8-16.

8. Nyamu, P. N., Otieno, C. F., Amayo, E. O. and McLigeyo, S. O. Patterns of diabetic foot ulcers at Kenyatta National Hospital. East Afr. Med. J. 2003; 80: 36-43.

9. Kenny, S. J., Smith, P. L., Goldschmid, M.G., et al. Survey of physician practice behaviors related to diabetes mellitus in the U.S. Diabetes Care. 1993; 16: 1507- 1509.

10. Peters, A. L., Legorreta, A. P., Ossorio, R. C. and Davidson, M.H.Quality of outpatient care provided to diabetic patients. Ahealth maintenance organization experience. Diabetes Care. 1996; 19: 601-603.

11. Pecoraro, R. E., Reiber, G. E. and Burgess, E. M. Pathways to diabetic limb amputation: basis for prevention. Diabetes Care. 1990; 13: 513-521.

12. Eckman, M.H., Greenfield, S. and Mackey, W. C. Foot infections in diabetic patients: decision and cost effectiveness analysis. J. Amer. Med. Assoc. 1995; 273: 712-720.

13. Edmonds, M. E. Improved survival of the diabetic foot. The role of a specialised foot clinic. Quarter. J. Med. 1986; 60: 763-771.

14. Mwendwa, F.M., Otieno, C.F., Amayo, E. O.et al. Risk factors profile and the occurrence of microvascular complications in type 2 diabetes at KNH. East Afr. Med. J. 2005; 82(suppl): S163- S172.

15. Morbach, S., Lutale, J. K., Viswanathan, V. et al. Regional differences in risk factors and clinical presentation of diabetic foot lesions. Diabet. Med. 2004; 21(1): 91-95.

16. Wikbald, K., Smide, B., Bergstrom, A., Kessi, J. and Mugusi, F. Outcome of clinical foot examination in relation to self perceived health and glycaemic control in a group of urban Tanzania diabetic patients. Diabetes. Res. Clin. Pract. 1997; 37: 185-192.

17. Elbagir, M., Mahadi, E. and Berne, C., Pattern or long term complication in Sudanese insulin-treated diabetic patients. Diabetes Res. Clin. Pract. 1995; 30:59-67.

18. Franklin, G. M., Kahn, L. B., et al. Sensory neuropathy in non insulin dependent diabetes mellitus, San Louis Valley Diabetes study. Amer. J. Epidem. 1990; 4: 633643.

19. Tesfaye, S. and Chaturvedi, N. Prospective study on diabetic complications in type 1 diabetics. N. Engl. J. Med. 2005; 352: 341-350.

20. Malik, M. Risk factors for diabetic foot. Turk. J. Sci. 1999; 2: 34-36.

21. Dyck, P.J., Kratz, K. M.et al. The prevalence by staged severity of various types or diabetic neuropathy, retinopathy, and nephropathy in a population-based cohort: The Rochester Diabetic Neuropathy Study. Neurology. 1993; 43: 817-824.

22. Isfahan, Endocrinology and Metabolism Research Group: Peripheral neuropathy in type 2 diabetes mellitus in Isfahan, Iran. Prevalence and risk factors; ISSN No. 1606-7754, 2006; 14: 1-3.

23. Diabetes Control and Complications Trial (DCCT) 
Research Group. The effect of intensive treatment of diabetes on the development and progression or longterm complications in insulin-dependent diabetes mellitus. N. Eng. J. Med. 1993; 329: 977-986.

24. Pickett, J.B. Motor conduction velocity - faster in women. Diabetologia. 1982; 23: 544-548.

25. American Diabetes Association. Implications of the United Kingdom Prospective Diabetes Study. Clin. Diabet. 1999; 17: 2180-2184.

26. Elizabeth, S., and Thomas, P. Prevalence of and risk factors for peripheral arterial disease in the United States (1999-2000). Circulation. 2004; 110: 738-743.

27. Andrew, S., Amanda, J. L. Role of systolic blood pressure and plasma triglycerides in diabetic peripheral arterial disease, The Edinburgh Artery Study. Diabetes Care. 1999; 22: 453-458.

28. Annunziata, L. and Francesco, P. Advanced glycation end products and antioxidant status in type 2 diabetic patients with and without peripheral artery disease. Diabetes Care. 2007; 30: 670-676.

29. Elizabeth, S. and Keatliyo, A. $\mathrm{HbA}_{1 \mathrm{c}}$ and peripheral arterial disease in diabetes, the atherosclerosis risk in communities study. Diabetes Care. 2006; 29: 877-882.
30. Abbas, M. and Husam, J. Foot abnormalities in diabetics, prevalence and predictors in Basrah, Iraq. Pak. J. Med. Sci. 2006; 22: 229-233.

31. Carine, H. and Van, S. Muscle weakness and foot deformities in diabetes relationship to neuropathy and foot ulceration in Caucasian diabetic men. Diabetes Care. 2004; 27: 1668-1673.

32. Singh, N., Armstrong, G. D. and Lipsky, B. A. Preventing foot ulcers in patients with diabetes. J. Amer. Med. Assoc. 2005; 293: 217-228.

33. Leese, G.P., Reid, F., Green, R.et al.Stratification of foot ulcers risks in patients with diabetes: a populationbased study. Int. J. Clin. Pract. 2006; 60: 541-545.

34. Boyko, E. J., Ahroni, J. H., Cohen, V. et al. Prediction of diabetic foot ulcers; occurrence using commonly available clinical information. The Seattle Diabetic Foot Study. Diabetes Care. 2006; 29: 1202-1207.

35. Lavery, L. A., Armstrong, D. G., Vela, S. A, et al. Practical criteria for screening patients at high risk for diabetic foot ulceration. Arch. Intern. Med. 1998; 158: $157-162$. 